\title{
Firm Subsidies and the Innovation Output: What Can We Learn by Looking at Multiple Investment Inputs?
}

\author{
Marco Cosconati ${ }^{1,2} \cdot$ Alessandro Sembenelli $^{3,4}$
}

Received: 3 July 2015 / Accepted: 2 November 2015 / Published online: 23 November 2015

(C) Società Italiana degli Economisti (Italian Economic Association) 2015

\begin{abstract}
In this paper we address the issue of if and how firm subsidies foster investment in fixed capital and R\&D and by doing so they contribute to the innovation output. We therefore extend the existing literature which so far has mostly focussed on the effects of public subsidies on specific innovation inputs. By using a rich dataset on Italian firms we estimate the relationships between inputs (investments) and innovation outputs (process and product) as well as investment equations in which expected firm subsidies affect the inputs. In order to deal with endogeneity issues we propose an empirical approach which exploits the information and characteristics of our dataset. We find that expected public intervention has an effect on investment in fixed capital and innovation. The impact of firm subsidies on $R \& D$ investment is found to be somehow weaker as well as its final effect on innovation.
\end{abstract}

Keywords Firm subsidies - R\&D and fixed investment - Product and process innovation

JEL Classification $\quad \mathrm{C} 23 \cdot \mathrm{H} 25 \cdot \mathrm{O} 32$

\footnotetext{
$\triangle$ Alessandro Sembenelli

alessandro.sembenelli@unito.it

1 Bank of Italy, Rome, Italy

2 IVASS, Rome, Italy

3 Università di Torino, Turin, Italy

4 Collegio Carlo Alberto, Moncalieri, Italy
} 


\section{Introduction}

The importance of innovation for companies and-ultimately-for aggregate economic growth is now understood by policy makers. ${ }^{1}$ In fact, innovation helps companies increase their productivity levels, enter new markets or stave off competition. It is now also commonly accepted that innovation comes in many different forms, ranging from a new product arising from $\mathrm{R} \& \mathrm{D}$ (product innovation) to efforts to incorporate innovative production equipment (process innovation), use new workplace practices (organizational innovation) or create new marketing concepts (marketing innovation). ${ }^{2}$ At a policy level the diversity of innovation causes difficulties in understanding the process as a whole and-ultimately-in designing appropriate innovation policies and monitoring their effectiveness.

In particular, most incentive schemes implicitly aimed at stimulating innovation output are designed with the main purpose of addressing market failures, such as externalities, imperfect information or coordination problems. Those are likely to affect specific factors, including R\&D and fixed investment, which enter the innovation process as inputs. Obviously, this approach has solid economic foundations and, indeed, there is general consensus among economists that market mechanisms fail to provide the socially optimal level of R\&D spending, basically because private firms are not able to fully capture all the profits arising from the results of their R\&D activity. Government intervention in this area is thus justified from an economic point of view by the market failure aspect of $R \& D$ : because the social returns to private $R \& D$ are often higher than the private returns, some research projects would benefit society but would be privately unprofitable. By lowering the cost to the firm, a subsidy can make these projects profitable as well. A somewhat related economic argument might also apply to fixed investment since the existence of financial constraints in some disadvantaged areas can lead to a sub-optimal capital accumulation level which in turn could be corrected by the implementation of appropriate incentive schemes.

Providing convincing evidence on the direct effect of public subsidies on R\&D and fixed investment is an important issue since both types of firm activities are found in the literature to be major determinants of firm innovation activities and ultimately of a country's growth prospects. ${ }^{3}$ Still, this evidence is not conclusive since it is the effect of subsidies on innovation outputs-as opposed to innovation inputs-what matters the most. The ability of incentive schemes to allocate funds to the highest return projects should clearly be at the center of the literature, but there is still little direct evidence on this issue. More specifically, we do not know much about the effect of public subsidies on the pace of technological progress, although the role of intermediaries-including public bodies-in selecting entrepreneurs with the best chances of introducing new products or processes is a key mechanism through which GDP growth is affected.

\footnotetext{
1 See, for instance, the emphasis that the European Union put on innovation as an engine for growth in the context of the so-called Lisbon strategy launched in March 2000.

2 The Oslo Manual (OECD 1992, 1996, 2005) defines precisely what is meant by innovation and provides a taxonomy of ways in which a firm can innovate.

3 See for instance Parisi et al. (2006).
} 
In this paper we contribute to this infant literature by providing empirical evidence on the impact of state aids on innovation through the increased incentives to invest in $\mathrm{R} \& \mathrm{D}$ and fixed investment. By doing so we allow for the possibility that process innovation-and to a lesser extent other forms of innovation as well- are introduced into the firm through gross investment in plants and equipments. ${ }^{4}$ Also, by considering the two inputs jointly, we explicitly recognize the role that R\&D investment may have in making possible and facilitating the absorption of innovations embodied in new capital goods purchased by the firm.

To this end it is required, as it is not done in the existing literature, that we model both the relationships between each type of innovation output and innovation inputs and the relationships between each innovation input and (a combination of) state aid types. ${ }^{5}$ We do so by using various waves of a rich survey on innovation at the firm level gathered by Unicredit's Research Department for a large number of Italian firms. ${ }^{6}$ This survey contains detailed categorical information on the introduction of process, product and organizational innovation. Moreover, it contains quantitative information on inputs of the innovation process at the firm level, such as R\&D spending and fixed investment, and on the way they are financed. In particular, we know whether a firm has benefitted from grants, tax credits or soft loans to finance R\&D or fixed investment, and also the contribution of each type of aid on total financing. Available information preclude us from focussing on specific incentive programs as it is usually done in the so-called "program evaluation" literature. Since one of the objectives of this paper is indeed to throw some light on how firms exploit multiple state aid opportunities and on how this affects innovation outputs this is not a limitation.

From a methodological point of view our empirical approach requires the estimation of three sets of equations, each posing difficult econometric challenges. Compared to the vast majority of existing literature, an important advantage of the data set we use is that we have repeated cross-sections which allow us, in principle, to control for the firm specific and time invariant component of the error term and to avoid-at least partly - the standard endogeneity problems brought about by the non-observability of managerial quality. An additional econometric problem is that the identification of causal effects without making independency assumptions between firm level unobserved heterogeneity and the covariates requires lack of correlation between the regressors and the idiosyncratic error term at all leads and lags. This strict exogeneity assumption rules out the possibility that current values of some of the explanatory variables are correlated with present and past idiosyncratic errors. This is unlikely to be the case in the present context since, for instance, a firm level technology shock might be correlated both with R\&D and fixed investment and with the probability of

\footnotetext{
4 This idea goes to back at least to Solow (1959) which makes the seminal distinction between "disembodied" and "embodied" technological progress, the latter typically measured by adjusting different vintages of the capital input for quality changes.

5 See however Czarnitzki and Licht (2006) and Czarnitzki et al. (2007) who focus on patent activity, Hussinger (2008) on new product sales and Bérubé and Mohnen (2009) on a number of variables proxying for product innovation.

6 This data set has been previously used for studying the effect of innovation on productivity (see Parisi et al. (2006)) and the effect of financial development on innovation (Benfratello et al. (2008)). To the best of our knowledge, however, information on public subsidies have not been exploited in depth yet.
} 
applying for and obtaining a public subsidy. Given the structure of our database, and indeed of most existing data-sets, there is no way of addressing this second concern in a fully satisfactory way. ${ }^{7}$ We address these issues by estimating an " expected subsidy" variable as a function of firm's observable characteristics. According to our main identifying assumption such a variable is exogenous in the $R \& D$ and fixed investment equations. ${ }^{8}$

This paper is organized as follows. Section 2 provides a brief and selective review of existing literature and highlights the main novelties of our work. In Sect. 3, we describe the data set we use for our investigation and we present some empirical regularities on public subsidies, R\&D and fixed investment, and innovation in our sample. Section 4 is the core of our paper where both the methodological approach and the empirical analysis are presented. Section 5 concludes the paper by summarizing the results and describing the additional questions that could be addressed in future research.

\section{Related Literature}

Our paper contributes—albeit not exclusively — to the vast empirical literature which aims at assessing the effect of public subsidies on firm $R \& D$ and fixed investment. As noted by Ientile and Mairesse (2009) in their extensive review on the effects of R\&D tax policies, the crucial issue in all this literature is the absence of a directly observable counterfactual, since the implementation of an experiment would imply that only some randomly selected firms receive the subsidy. This research strategy is not feasible in most industrialized countries since it distorts competition and therefore violates competition law. In turn, this presents a serious challenge to econometric analysis since in a standard investment equation the received subsidy is clearly endogenous. This is because of simultaneity and selection bias in the observed funding process or because there are omitted variables which are potentially correlated both with the decision of undertaking R\&D activities and with the decision of applying to and obtaining a public subsidy.

David et al. (2000) survey the older literature on the impact of public R\&D firm subsidies on private $R \& D$ expenditures and conclude that at that time selectivity of funded firms into public funding was largely ignored. A useful way to provide a brief but informative review of the more recent literature is therefore to use as organizing principle a simple taxonomy of the different methodologies used to tackle the above mentioned econometric issues. The methods employed include non-parametric matching, difference-in-difference estimator, control function approaches (selection models) and IV estimation. ${ }^{9}$ All of these methodologies have advantages and disadvantages and the choice of the "appropriate" econometric method very often turns out to depend—over and beyond researchers' idiosyncratic preferences—on the data-set

\footnotetext{
7 This is the case because only a very limited number of firms is present in all three consecutive waves we consider. This, for instance, makes the application of the standard GMM-first difference approach practically unfeasible.

8 An economic model consistent with this approach is presented in González et al. (2005).

9 To save on space we confine ourselves to the international literature which focuses on R\&D investment and innovation. Most of the comments apply to the empirical literature on fixed investment as well.
} 
on which it is applied. Data on R\&D and innovation, including public subsidies, are commonly taken from innovation surveys which are of a cross-sectional nature. As a matter of fact it is always very difficult to address endogeneity issues and therefore make sensible statements on the directions of causality with cross-sectional data. Many of the relevant variables in innovation surveys concern firm strategic decisions: doing $R \& D$, introducing innovation and applying for financial support. All these decisions are determined simultaneously and are jointly dependent on unobservable factors. Furthermore, only rarely we have variables which can be used as valid and relevant instruments. In principle, significant steps forward could be achieved with panel data. It is however difficult to construct panel data samples by merging consecutive innovation surveys because they are not performed on a yearly basis and variables are often observed at different frequencies. Moreover, they are typically based on a stratified sample design with dimensions that are relevant to the economic question addressed. This in turn might induce selectivity in the sample that may be differential overtime. $^{10}$

The pioneering study by Wallsten (2000) investigates the effect on private R\&D of the Small Business Innovation Research (SBIR) program implemented in the US. To address the endogeneity problem, he implements a small system of equations in which the endogenous award variable is instrumented with a variable proxying for the funds that are potentially awardable to the firm. He finds evidence that the grants crowd out firm-financed R\&D spending dollar per dollar. Busom (2000) addresses the same economic issue by using a cross-section of Spanish firms conducting R\&D activities. She addresses the problem of selection bias by applying a two-stage control function approach. In the first stage, she estimates a binary response model on the participation probability in public funding programs. In the second stage, the R\&D activity is regressed against a set of covariates which include a selection term capturing differences in firm propensities to have access to public funds. The main finding of this paper is that public funding induces more private effort even if for some firms full crowding out effects cannot be ruled out.

Lack (2002) is the first paper to apply a conditional difference-in-difference (DID) strategy to analyze the effect of public subsidies on R\&D expenditures. This was made possible by the availability of a longitudinal data-set collecting information on a sample of Israeli's R\&D active firms per year. This methodological approach handles the problem caused by the likely fact that more successful firms might receive more $\mathrm{R} \& \mathrm{D}$ subsidies and do more $\mathrm{R} \& \mathrm{D}$, provided that managerial quality is roughly constant during the sample period and it is therefore differenced out in the DID estimator. This estimator however is biased for the parameter of interest when obtaining a public subsidy is associated with unobserved idiosyncratic technology shocks which also lead to more R\&D expenditures. He finds evidence that R\&D subsidies granted by the Israeli's Ministry of Industry and Trade greatly stimulated firm private R\&D expenditures for small firms but had a negative-albeit not significant-effect on the R\&D of large firms.

10 Mairesse and Mohenen (2010) discuss in detail the characteristics of the data innovation surveys usually contain and the challenges they pose to econometric analysis. 
In a number of related papers Czarnitzki and various co-authors also focus on crowding-out effects and introduce to this literature the non-parametric matching approach previously applied extensively to the literature on the evaluation of active labor market policies. In particular, Almus and Czarnitzki (2003) use-albeit without fully exploiting the longitudinal dimension - three waves of the Mannheim Innovation Panel and investigate the average causal effect of all public R\&D schemes in Eastern Germany by using firm level R\&D intensity as potential outcome variable. Compared to the case in which no public funding is provided, they find that benefitting firms increase their R\&D activities by four percentage points. In a following paper, Czarnitzki and Licht (2006) question whether this additional innovation input induced by public policy fosters innovation output, as measured by patent applications for both Eastern and Western Germany. In fact, as they correctly point out, it might well be possible that $R \& D$ public subsidies could also be spent inefficiently or alternatively be invested in extremely risky projects and therefore not to lead to an increase in output. They find a large degree of additionality both in innovation inputs measured as R\&D or innovation expenditures and in innovation output as measured by the propensity to patent and the number of patent applications. Finally, Czarnitzki et al. (2007) investigate whether R\&D public subsidies and R\&D cooperation affect both R\&D and patenting activities using a sample of Western German and Finnish firms extracted from national Community Innovation Surveys (CIS). They consider the receipt of public subsidies and the participation to $R \& D$ cooperative efforts as heterogeneous treatments in order to be able to disentangle the two effects. The main conclusion they draw from their analysis is that in Finland both firm subsidies and cooperation activities have a positive impact on treated firms. In Germany, however, only cooperation and the combination of public subsidies with cooperative activities show significant effects.

González et al. (2005) is somehow closer in spirit to our approach. The authors develop a static model of investment decisions in R\&D in which some government support is expected and test it against an unbalanced panel of Spanish manufacturing firms surveyed during the period 1990-1999. In short, each firm is considered as a product-differentiated competitor which faces a downward sloping demand function. In this context, R\&D activity enters as a demand shifter by enhancing product quality. Given the presence of set up costs of R\&D projects, there is a profitability threshold under which firms find it optimal not to perform any research activity, since R\&D costs are not fully recovered trough additional sales. This decision can however change if expected subsidies reduce the cost of R\&D. The same argument also explains why R\&D performing firms take expected subsidies into consideration when choosing the optimal size of planned R\&D expenditures. In practice, the authors estimate expected subsidies and use them in explaining R\&D participation and R\&D effort by applying econometric methods which deal with selectivity and endogeneity. The structural model allows the authors to establish to what extent firms would have not initiated projects had the subsidies not been given. Results suggest that subsidies stimulate $\mathrm{R} \& \mathrm{D}$ although most firms that receive subsidies would have performed R\&D anyway. In addition they find no crowding out of private funds.

More recently, Hussinger (2008) analyzes the effect of public R\&D subsidies on firms' private R\&D investment and new product sales in German manufacturing. As 
in several previous studies reviewed so far, the underlying database is the Mannheim Innovation Panel (MIP). She applies parametric and semiparametric two-step selection models, which relax the standard normality assumption of the error term, and finds that the average treatment effect on the treated firms is positive when R\&D investment per employee is chosen as the outcome variable. In addition, this result is robust to alternative choices of semiparametric estimators. Interestingly for the purpose of our paper, she also regresses a variable proxying for product innovation, namely firm level new product sales, on both private $R \& D$ investment per employee and the average treatment effect, set to zero for firms that do not receive public subsidies. A parametric test does not reject the hypothesis of equal coefficients of private and publicly induced $\mathrm{R} \& \mathrm{D}$ investment. In turn this suggests that they are equally productive in terms of new product sales.

Aerts and Schmidt (2008) also test whether public R\&D subsidies crowd out private R\&D investment in Flanders and Germany by using two consecutive waves of the national Innovation Community Surveys (CIS). The main methodological innovation of their paper is that they check the robustness of their results to alternative estimation methods. Operationally, the authors first use a non-parametric matching estimator which they apply only to a cross-sectional sample. As it is well known, the disadvantage of this estimator is that it does not control for any form-both permanent and transitory — of unobserved heterogeneity. To address this legitimate concern, they also exploit the longitudinal dimension and apply a combination of the matching procedure and the difference-in-difference (DID) methodology, known as conditional difference-in-difference (CDID). They find that the crowding-out hypothesis can be clearly rejected since funded firms are significantly more research active compared to non-funded firms. Moreover, this applies to both countries and holds for both estimation strategy.

Bérubé and Mohnen (2009) is, to the best of our knowledge, the only published paper which focuses primarily on innovation output. This paper looks at the effectiveness of R\&D grants by comparing innovation performance measures between firms that received $R \& D$ tax credits only and firms that received both $R \& D$ tax credits and $R \& D$ grants. Using a non-parametric matching estimator and data from the 2005 Survey of Innovation from Statistics Canada they find that using tax credits and grants is more effective than using tax credits only, since firms benefitting from both types of incentives are found to introduce more new products, to make more world-first product innovations and to be more successful in commercializing their innovations.

Finally, we believe that our work expands the existing literature in at least three dimensions. First we do not consider investments per se as the ultimate outcome of interest and instead, in our effort to estimate interesting quantities which can highlight the cost and benefit of state aids, we also look at the direct effect of investments on innovation. Secondly, we look at product and process innovation, a distinction which is often neglected in the literature and yet, in light of our results, a relevant one. Finally, from the methodological viewpoint we try to deal with potential omitted variable problems in our innovation production function by exploiting the longitudinal aspects of our data, a unique feature of the information we possess. In practice this translates into the implementation of fixed effects and random effects estimators which, under assumptions we specify and discuss, can consistently estimate the marginal return 
of investments on innovation. This approach is conceptually different than the DID and CDID estimators we described. For what concerns the impact of state aids on investments, we are close in spirit to the approach of González et al. (2005), which we adapt to our context by clarifying under which assumptions we can uncover the causal effect of state aids on investment.

\section{Data}

The data-set we employ in the analysis consists of three waves which report the responses on a set of items asked to managers of a large sample of Italian manufacturing firms. For our purposes the data contain rich information on the amount of investments in R\&D and fixed capital, whether the firm introduced a product and/or process innovation as well as the proportion of total cost related to $R \& D$ and fixed investment financed by state aids in the form of soft loans, tax credits and grants. The three waves contain information for the following time periods: 1998-2000, 20012003, and 2004-2006.

In each wave the sample is selected (partly) with a stratified method for firms below 500 workers, whereas firms above this threshold are all included. Strata are based on geographical area, industry, and firm size. It is not completely clear, however, that the stratification criteria have remained constant over time. Moreover, some firms are added to the sample outside the stratification criteria. This may explain-together with macroeconomic fluctuations-why one observes a substantial variation in the average and median size of the firms included in the sample, which makes it unfeasible to use aggregate wave statistics to track the evolution of relevant variables at the economy level. The sampling procedure is as such that not all the firms are present in all of the three waves: new firms are sampled in the second and third wave and some leave the sample either in the second or third wave. Table 1 shows that out of the 10,588 firms for which we have information in at least one wave only 435 are present in all of the three waves. For 2220 we have two consecutive data points. Firm size, as measured by sales is described in Table 2, which shows that both average and median size have a large drop in the third wave.

Table 3 reports, separately for each wave, the percentage of firms investing in fixed and $R \& D$ capital. As it can be seen, this percentage is substantial for fixed capital

Table 1 Panel structure

\begin{tabular}{lcc}
\hline & No. of firms & Frequencies \\
\hline Only third wave & 3783 & 35.7 \\
Only first wave & 2327 & 22.0 \\
Only first and second waves & 1640 & 15.5 \\
Only second wave & 1591 & 15.0 \\
Only second and third waves & 580 & 5.5 \\
All the waves & 435 & 4.2 \\
Only first and third waves & 232 & 2.1 \\
Total & 10,588 & 100.0 \\
\hline
\end{tabular}


Table 2 Triennial sales in million euros

\begin{tabular}{llll}
\hline & $1998-2000$ & $2001-2003$ & $2004-2006$ \\
\hline Number of firms & 4610 & 4005 & 5026 \\
Mean & 71.7 & 89 & 56.3 \\
Standard deviation & 188.7 & 203.3 & 147.6 \\
1st quartile & 12.2 & 12.9 & 8.9 \\
Median & 21.4 & 29.4 & 16.7 \\
3rd quartile & 46.5 & 67.1 & 39.8 \\
\hline
\end{tabular}

Table 3 Firms with positive investment spending

\begin{tabular}{llllll}
\hline & \multicolumn{2}{l}{ Fixed investment $(\mathrm{FI})$} & & \multicolumn{2}{l}{ R\&D investment } \\
\cline { 2 - 3 } & Obs & Obs with FI $>0(\%)$ & & Obs & Obs with R\&D $>0(\%)$ \\
\hline $1998-2000$ & 4634 & 91.0 & 4572 & 37.7 \\
$2001-2003$ & 4242 & 85.9 & 4136 & 45.6 \\
$2004-2006$ & 5030 & 72.0 & 5030 & 33.7 \\
\hline
\end{tabular}

Table 4 Triennial fixed and R\&D investment in million euros (conditional on non-zero investment)

\begin{tabular}{|c|c|c|c|c|c|c|}
\hline & \multicolumn{3}{|c|}{ Fixed investment } & \multicolumn{3}{|c|}{ R\&D investment } \\
\hline & 1998-2000 & 2001-2003 & 2004-2006 & 1998-2000 & 2001-2003 & 2004-2006 \\
\hline Number of firms & 3376 & 3334 & 1901 & 1396 & 1473 & 1696 \\
\hline Mean & 3.8 & 2.6 & 2.1 & 1.8 & 1.2 & 0.7 \\
\hline Standard deviation & 11.4 & 5.9 & 5.3 & 7.5 & 3.3 & 1.6 \\
\hline 1st quartile & 0.3 & 0.2 & 0.1 & 0.1 & 0.1 & 0.1 \\
\hline Median & 0.9 & 0.6 & 0.6 & 0.3 & 0.3 & 0.2 \\
\hline 3rd quartile & 2.5 & 2.2 & 1.9 & 0.9 & 0.9 & 0.6 \\
\hline
\end{tabular}

(ranging from 72 to $91 \%$ ) whereas there is a large percentage of firms which are not engaged in formal R\&D activity: more than half of the firms show in fact zero R\&D spending in most periods (ranging from 54.4 to $66.3 \%$ ). This is hardly surprising given the structure of Italian manufacturing characterized by a large number of small firms operating in low-medium tech industries. The conditional distribution of investments is shown in Table 4. What we observe is a steady decline over time in the average size of both investment types. This decline is, however, less pronounced if one looks at the quantiles of the empirical distributions. In particular, R\&D conditional distributions look very similar over time whereas a mild decline is observed in all quantiles of the conditional distributions for fixed investment.

Our data-set provides unusually rich information on the type of state aid the firm benefitted from as well as the proportion of the investment financed by such a source. The questionnaire elicits self-reported information about three specific forms of incentives: soft loans, tax credits and grants. Table 5 reports the share of beneficiaries for both investment activities and by type of subsidy. Overall, the share of benefitting 
Table 5 Share of benefitting firms

\begin{tabular}{llll}
\hline & $1998-2000$ & $2001-2003$ & $2004-2006$ \\
\hline $\begin{array}{l}\text { Fixed investment } \\
\text { No. of firms with } \\
\text { available financial } \\
\text { data }\end{array}$ & 4154 & 3465 & 3203 \\
$\quad$ Grants (\%) & 16.3 & 16.4 & 2.3 \\
$\quad$ Tax credits (\%) & 24.4 & 18.5 & 3.3 \\
$\quad$ Soft loans (\%) & 11.8 & 15.2 & 14.9 \\
R\&D investment & & & \\
$\quad$ No. of firms with & 1662 & 1806 & 1326 \\
$\quad$ available financial & & & \\
$\quad$ data & & 18.2 & 5.1 \\
Grants (\%) & 15.5 & 9.9 & 5.1 \\
$\quad$ Tax credits (\%) & 13.3 & 6.2 & 13.9 \\
$\quad$ Soft loans (\%) & 5.7 & & \\
\hline
\end{tabular}

firms in our sample can be considered as substantial in all three waves even if one observes a large drop in the proportion of firms which obtained grants or tax credits in the third wave. This reduction is coherent with the aggregate fall in state aids granted by Italian authorities in the final years of our sample period, also as a consequence of fiscal policy tightening. Table 5 also shows that for what concerns the investments in fixed capital (top part of the table) many firms in the first and second wave used tax credits which is used more often than soft loans and grants. Grants are the most used type of state aid to finance investment in $R \& D$ in the first two waves whereas soft loans prevail in the third wave (bottom part of the table).

A virtue of our data is also to provide additional information on the amount of each source of state aid, which is usually not observed in comparable data-sets such as the Community Innovation Survey (CIS). Summary statistics on this issue are provided in Table 6 which shows the substantial amount of variation in the share of investment funded with public subsidies. For example, in the first wave the share of fixed investment subsidized with grants ranges from 10 (first quartile) to $40 \%$ (third quartile). The availability of such detailed information also allows us to assess the extent to which firms benefit from different types of subsidies in the same time period. Relevant results are summarized in Table 7 which reveals that many firms benefit from more than one instrument. For instance, in the first wave 557 firms (out of 1587) made use of a single instrument whereas 399 benefitted from multiple instruments when considering R\&D and fixed investment jointly. Finally, as documented in Tables $8,9,10,11,12$ and 13, for any type of state aid and in all the periods we observe non trivial dynamic patterns in our data-set: the cells off-diagonal of the transitions matrix are non-empty. For instance, of the firms who had received a grant to finance fixed investment in the first/second wave, $81.3 \%$ do not receive such an aid in the second/third wave. Symmetrically, of the firms who had not receive a grant in the first period, around $10.2 \%$ would receive such an aid in the second/third wave. Clearly 
Table 6 Share of subsidies on total financing (\%)

\begin{tabular}{|c|c|c|c|c|c|c|c|c|c|c|c|c|}
\hline & \multicolumn{4}{|c|}{ 1998-2000 } & \multicolumn{4}{|c|}{ 2001-2003 } & \multicolumn{4}{|c|}{ 2004-2006 } \\
\hline & No. & 1st Q & 2nd Q & 3rd Q & No. & 1st Q & 2nd Q & 3rd Q & No. & 1st Q & 2nd Q & 3rd Q \\
\hline \multicolumn{13}{|c|}{ Fixed investment } \\
\hline Grants & 678 & 10 & 20 & 40 & 569 & 8 & 10 & 30 & 72 & 10 & 25 & 50 \\
\hline Tax credits & 1014 & 10 & 20 & 34 & 642 & 8 & 15 & 30 & 106 & 20 & 25 & 40 \\
\hline Soft loans & 492 & 20 & 43 & 70 & 527 & 20 & 40 & 60 & 477 & 30 & 50 & 100 \\
\hline \multicolumn{13}{|c|}{ R\&D investment } \\
\hline Grants & 257 & 10 & 30 & 50 & 328 & 10 & 20 & 50 & 68 & 15 & 30 & 50 \\
\hline Tax credits & 221 & 10 & 25 & 50 & 178 & 10 & 20 & 50 & 67 & 15 & 50 & 80 \\
\hline Soft loans & 94 & 20 & 47 & 80 & 112 & 20 & 50 & 80 & 184 & 50 & 100 & 100 \\
\hline
\end{tabular}

Table 7 Types of instruments (conditional on non-zero investment)

\begin{tabular}{|c|c|c|c|c|c|c|c|c|c|}
\hline & \multicolumn{3}{|c|}{ 1998-2000 } & \multicolumn{3}{|c|}{ 2001-2003 } & \multicolumn{3}{|c|}{ 2004-2006 } \\
\hline & Fix inv & $\mathrm{R} \& \mathrm{D}$ inv & Total & Fix inv & $\mathrm{R} \& \mathrm{D}$ inv & Total & Fix inv & $\mathrm{R} \& \mathrm{D}$ inv & Total \\
\hline No. of firms & 4154 & 1662 & 1587 & 3465 & 1806 & 1659 & 3203 & 1326 & 959 \\
\hline 0 instrument & 2349 & 1171 & 631 & 2087 & 1256 & 753 & 2589 & 1036 & 637 \\
\hline 1 instrument & 1460 & 420 & 557 & 1066 & 481 & 527 & 579 & 270 & 232 \\
\hline 2 instruments & 311 & 61 & 283 & 264 & 61 & 268 & 29 & 11 & 74 \\
\hline 3 instruments & 34 & 10 & 80 & 48 & 5 & 60 & 6 & 9 & 13 \\
\hline$>3$ instruments & & & 36 & & & 51 & & & 3 \\
\hline
\end{tabular}

Table 8 Transitions in fixed investment (FI) grants

Table 9 Transitions in FI tax

exemptions

\begin{tabular}{llll}
\hline & \multicolumn{2}{l}{ Grants W2/W3 } & \\
\cline { 2 - 4 } Grants W1/W2 & 0 & 1 & Total \\
\hline 0 & 1938 & $\mathbf{2 2 1}$ & 2159 \\
Percentage & 89.76 & 10.24 & 100.00 \\
1 & $\mathbf{3 7 3}$ & 86 & 459 \\
Percentage & 81.26 & 18.74 & 100.00 \\
\hline
\end{tabular}

\begin{tabular}{llll}
\hline & \multicolumn{2}{l}{ Fiscal W2/W3 } & \\
\cline { 2 - 4 } Fiscal W1/W2 & 0 & 1 & Total \\
\hline 0 & 1784 & $\mathbf{2 0 5}$ & 1989 \\
Percentage & 89.69 & 10.31 & 100.00 \\
1 & $\mathbf{5 0 8}$ & 121 & 629 \\
Percentage & 80.76 & 12.45 & 100.00 \\
\hline
\end{tabular}

these statistics suggest the possibility to exploit the within firm variation to control for unobserved heterogeneity. 
Table 10 Transitions in FI subsidized int rate aids

Table 11 Transitions in R\&D grants

Table 12 Transitions in R\&D tax exemptions

Table 13 Transitions in R\&D subsidized int rate aids

\begin{tabular}{llll}
\hline & \multicolumn{2}{l}{ Interate W2/W3 } & Total \\
\cline { 2 - 4 } Interate W1/W2 & 0 & 1 & 2236 \\
\hline 0 & 2016 & $\mathbf{2 2 0}$ & 100.00 \\
Percentage & 90.16 & 9.84 & 382 \\
1 & $\mathbf{3 1 6}$ & 66 & 100.00 \\
Percentage & 82.72 & 17.28 & \\
\hline
\end{tabular}

\begin{tabular}{llll}
\hline & \multicolumn{2}{l}{ Grants W2/W3 } & \\
\cline { 2 - 4 } Grants W1/W2 & 0 & 1 & Total \\
\hline 0 & 770 & $\mathbf{1 0 1}$ & 871 \\
Percentage & 88.40 & 11.60 & 100.00 \\
1 & $\mathbf{1 7 5}$ & 51 & 226 \\
Percentage & 77.43 & 22.57 & 100.00 \\
\hline
\end{tabular}

\begin{tabular}{llll}
\hline & \multicolumn{2}{l}{ Fiscal W2/W3 } & \\
\cline { 2 - 4 } Fiscal W1/W2 & 0 & 1 & Total \\
\hline 0 & 898 & $\mathbf{4 9}$ & 947 \\
Percentage & 94.83 & 5.17 & 100.00 \\
1 & $\mathbf{1 3 0}$ & 20 & 150 \\
Percentage & 86.67 & 13.33 & 100.00 \\
\hline
\end{tabular}

\begin{tabular}{llll}
\hline \multirow{2}{*}{ Interate W1/W2 } & \multicolumn{3}{l}{ Interate W2/W3 } \\
\cline { 2 - 4 } 0 & 0 & 1 & Total \\
\hline Percentage & 967 & $\mathbf{5 6}$ & 1,023 \\
1 & 94.53 & 5.47 & 100.00 \\
Percentage & $\mathbf{6 4}$ & 10 & 74 \\
& 86.49 & 13.51 & 100.00 \\
\hline
\end{tabular}

Table 14 Number of innovative firms

\begin{tabular}{|c|c|c|c|c|c|c|}
\hline & \multicolumn{2}{|c|}{ 1998-2000 } & \multicolumn{2}{|c|}{ 2001-2003 } & \multicolumn{2}{|c|}{ 2004-2006 } \\
\hline & No. & $\%$ & No. & $\%$ & No & $\%$ \\
\hline Product innovation & 1147 & 35.0 & 1732 & 53.8 & 2470 & 52.0 \\
\hline Process innovation & 1721 & 44.7 & 1769 & 54.3 & 2145 & 45.1 \\
\hline
\end{tabular}

We also observe many firms introducing innovations. For example, as Table 14 shows, $35 \%$ of the firms introduce a product innovation in 1998-2000 and $44.7 \%$ introduce a process innovation in the same time period. From this table it is transparent how substantial the innovation process is in our data-set for all the three periods we have. Moreover, as it is the case for the event of receiving a public subsidy, we observe a 
Table 15 Transitions in product innovation

Table 16 Transitions in process innovation

\begin{tabular}{llll}
\hline & \multicolumn{3}{l}{ Product innovation $\mathrm{W} 2 / \mathrm{W} 3$} \\
\cline { 2 - 4 } Product innovation W1/W2 & 0 & 1 & Total \\
\hline 0 & 657 & $\mathbf{4 4 3}$ & 1,100 \\
Percentage & 59.73 & 40.27 & 100.00 \\
1 & $\mathbf{3 1 7}$ & 691 & 1800 \\
Percentage & 31.45 & 68.55 & 100.00 \\
\hline
\end{tabular}

\begin{tabular}{llll}
\hline & \multicolumn{3}{l}{ Process innovation W2/W3 } \\
\cline { 2 - 4 } Process innovation W1/W2 & 0 & 1 & Total \\
\hline 0 & 667 & $\mathbf{4 2 0}$ & 1,087 \\
Percentage & 61.36 & 38.64 & 100.00 \\
1 & $\mathbf{4 8 2}$ & 720 & 1202 \\
Percentage & 40.10 & 59.9 & 100.00 \\
\hline
\end{tabular}

Table 17 Regressions of investments on firm subsidies with aggregate time dummies

\begin{tabular}{|c|c|c|c|c|}
\hline Method & $\begin{array}{l}\text { Pooled OLS } \\
\text { (1) } \\
\text { lfixinv }\end{array}$ & $\begin{array}{l}\text { "Fixed" effect } \\
\text { (2) } \\
\text { lfixinv }\end{array}$ & $\begin{array}{l}\text { Pooled OLS } \\
\text { (3) } \\
\text { lrdinv }\end{array}$ & $\begin{array}{l}\text { "Fixed" effect } \\
\text { (4) } \\
\text { lrdinv }\end{array}$ \\
\hline lsales & $0.863 * * *(0.012)$ & $0.447 * * *(0.103)$ & $0.724 * * *(0.017)$ & $0.344 * *(0.165)$ \\
\hline dgrants & $0.489 * * *(0.041)$ & $0.217 * * *(0.069) * * *$ & & \\
\hline dfiscal & $0.408 * * *(0.036)$ & $0.209 * * *(0.064)$ & & \\
\hline dinterate & $0.323 * * *(0.040)$ & $0.187 * *(0.080)$ & & \\
\hline drgrants & & & $0.624 * * *(0.056)$ & $0.263 * *(0.110)$ \\
\hline drfiscal & & & $0.460 * * *(0.068)$ & $0.205 *(0.122)$ \\
\hline drinterate & & & $0.093(0.072)$ & $0.330 * *(0.156)$ \\
\hline constant & $-2.979 * * *(0.257)$ & $1.570(1.048)$ & $-1.401 * * *(0.308)$ & $2.081(1.716)$ \\
\hline $\mathrm{N}$ & 8119 & 8119 & 4214 & 4214 \\
\hline
\end{tabular}

Robust standard errors in round brackets

$* p<0.10$

$* * p<0.05$

$* * * p<0.01$

lot of transitions as it is documented in Tables 15 and 16. Once again, this is comforting, since it allows us to exploit the within-firm variation in our econometric exercise.

\section{Empirical Evidence}

We structure our empirical work as follows. First we want to show how the event of receiving a subsidy is related to the amount of investments in fixed capital and $\mathrm{R} \& \mathrm{D}$ and to what extent this association is robust to different assumptions on the conditional distribution of the error term. The results are contained in Table 17. We then turn our attention to the impact of state aids on innovation. This issue requires 
the estimation of two sets of parameters related to two types of relationships. First, we need to estimate two innovation production functions, which relate investments of different types to the probability of introducing a product or a process innovation. This is accomplished in Sect. 4.3. In this context the parameters we estimate are to be interpreted as the marginal productivity of the inputs we measure. Second, we need to estimate the relationships which map state aids into the amount of R\&D and fixed investment decided by the firm, which we interpret as an approximation of the investment decision rule of the firm. We do so adopting an approach akin to a two step procedure. In the first step, described in Sect. 4.4, we predict expected aids. In the second step, described in Sect. 4.5, we estimate the relationship between expected aids and investment decisions. We now discuss the identification challenges we face more in detail.

\subsection{Identification}

The identification of the parameters present in both these relationships is threatened by several endogeneity problems. In particular, the estimation of innovation production functions requires to take into account the endogenous nature of the inputs which may be correlated both with permanent unobserved heterogeneity and with the idiosyncratic component of the error term. The former can be thought in terms of firm unobservable characteristics which are not time-varying, e.g. managerial ability, while the latter as random opportunities which make innovation less or more profitable. In principle, the longitudinal aspect of our data-set allows us to eliminate the "fixed effect" component by applying the conditional logit estimator. The price one has to pay is that only switchers contribute to the likelihood and this in turn can affect precision in a substantial way. The second task is much more difficult, also because of the discrete nature of our dependent variables. Even in a more standard linear framework, however, it would not be obvious how to solve this problem in a fully satisfactory way given the short dimension of our panel and the unavailability of convincing external instruments. We also face similar endogeneity problems when we estimate the investment equations: in fact the amount of state aids is likely to be correlated both with the unobserved heterogeneity component and with the idiosyncratic part of the error term. The approach we take here is to model the investment decisions as a function of expected subsidies, to estimate this expectation as a function of observables and to state and discuss explicitly the identifying assumptions underlying this estimation strategy. We now describe and discuss our empirical results.

\subsection{Investments and Funding Opportunities}

Table 17 shows the results of various regressions of the log of investments in fixed capital and R\&D (lfixinv and lrdinv) on firm size (the log of sales) and dummies for whether the firm had access to grants to fixed investments and R\&D (dgrants and drgrants), to tax credits (dfiscal and drfiscal) as well as soft loans (dinterate and drinterate). In running these regressions we also included time dummies and, whenever appropriate, area dummies and industry dummies which are omitted from the table. These additional regressors capture aggregate shocks as well as industry-specific and 
geographical time-invariant effects. Columns 1 and 3 show how in a simple pooled OLS regression state aids which are specific to a given type of investment are positively correlated to the latter. Under the assumption that all the relevant sources of unobserved heterogeneity are included in the regressors the pooled OLS regression would yield consistent estimates of the impact of state aids on investments. ${ }^{11}$ We find that having access to grants/tax credits translates into an increase of about $40 \%$ in capital spending. The response of investments in $R \& D$ is even higher: the coefficients attached to drgrants and drfiscal are 0.6 and 0.4 , respectively.

A more satisfactory econometric model is implemented in columns 2 and 4 . The "fixed" effect model allows for an arbitrary correlation structure between the individual effect and the regressors. ${ }^{12}$ This key endogeneity issue is addressed by applying the standard within-group transformation which removes the individual effect. Our results somehow change in the sense that the parameters are less precisely estimated. However the same basic qualitative message arises: more firm incentives are associated with a greater amount of investments. In this case, however, the value of the estimates gets diminished by roughly $50 \%$, thus empirically confirming the upper bias in the relevant parameters arising from the omission of the time invariant component of managerial quality. For example, the partial elasticity of fixed investments with respect to sales drops from 0.8 to $0.4 \%$ when we take into account permanent unobserved heterogeneity. ${ }^{13}$ The results from the fixed effect estimator indicate that if the firm has access to grants/tax credits the investment in fixed capital increase by roughly $20 \%$. The estimates of the effect of aids on investments in R\&D are similar in magnitude although drfiscal is significative only at the $10 \%$ significance level.

Although these result are informative about the strength of the mechanisms we are analyzing, it is still quite possible that they overestimate the "true" effect since they do not take into account the likely correlation between the idiosyncratic component of the error term and state aids. Indeed, industry or firm specific technology shocks are likely to affect both R\&D and fixed capital spending and the probability of applying to and obtaining a subsidy. A useful-albeit partial-step in the right direction is therefore to allow for industry specific time effects capturing the industry specific component of technology shocks. In order to do so we also included dummies interacting industry and time. These additional regressors are obviously not eliminated once we apply the within group transformation. As we can see from Table 18 the results obtained in Table 17 are robust to the inclusion of these additional regressors. It is then reasonable to conclude that the correlation of subsidies and industry specific shocks is not contaminating our previous results.

Taken at face value our results so far indicate that (i) the sign of the correlations between firm subsidies and both fixed and R\&D investment is positive thus according to the favorable view of the role of public subsidies in stimulating investment, (ii)

\footnotetext{
11 The same results hold when we consider a random effect model which, with respect to the OLS regression, takes into account the structure of the error term to improve on efficiency. The coefficients are similar to the ones we got in the OLS model. This method, however, is still based on the assumption that the expected value of the individual effect is uncorrelated with each and every covariate.

12 In this case the within group transformation eliminates the industry and area dummies.

13 By partial elasticity we mean the elasticity one obtains holding everything else constant.
} 
Table 18 Regressions of investments on firm subsidies with industry specific time dummies

\begin{tabular}{|c|c|c|c|c|}
\hline Method & $\begin{array}{l}(1) \\
\text { Pooled OLS } \\
\text { lfixinv }\end{array}$ & $\begin{array}{l}(2) \\
\text { "Fixed effect" } \\
\text { lfixinv }\end{array}$ & $\begin{array}{l}(3) \\
\text { Pooled OLS } \\
\text { lrdinv }\end{array}$ & $\begin{array}{l}(4) \\
\text { "Fixed effect" } \\
\text { lrdinv }\end{array}$ \\
\hline lsales & $0.865 * * *(0.012)$ & $0.554 * * *(0.099)$ & $0.724 * * *(0.017)$ & $0.348 * *(0.169)$ \\
\hline dgrants & $0.492 * * *(0.041)$ & $0.223 * * *(0.069)$ & & \\
\hline dfiscal & $0.409 * * *(0.036)$ & $0.213 * * *(0.065)$ & & \\
\hline dinterate & $0.319 * * *(0.040)$ & $0.185 * *(0.081)$ & & \\
\hline drgrants & & & $0.603 * * *(0.056)$ & $0.202 *(0.112)$ \\
\hline drfiscal & & & $0.443 * * *(0.068)$ & $0.167(0.119)$ \\
\hline drinterate & & & $0.089(0.072)$ & $0.333 * *(0.156)$ \\
\hline constant & $-2.933 * * *(0.268)$ & $1.062(1.046)$ & $-1.426 * * * 0.324$ & 1.8381 .039 \\
\hline $\mathrm{N}$ & 8119 & 8119 & 4214 & 4214 \\
\hline
\end{tabular}

Robust standard errors in round brackets

Wave, industry and area dummies are omitted

$* p<0.10$

$* * p<0.05$

$* * * \quad p<0.01$

the estimates of the impact of state aids on investments in R\&D and fixed capital inflates the impact of state aids if we do not take into account the correlation between unobserved heterogeneity and the aids themselves, (iii) controlling for industry specific technology shocks does not change our baseline results in a significant way.

It is important to recognize that the results we presented are questionable if, even after applying the within group transformation and controlling for industry-specific technology shocks, the error term is correlated with public subsidies. For instance, if a new engineer is hired by a firm and this expands the idiosyncratic technological opportunities of the hiring firm, its incentives both to invest and to apply to public subsidies are likely to be fostered. In order to address this remaining legitimate concern, we develop a simple econometric framework in the next section in which firm decisions on fixed and R\&D new capital are taken as a function of an observable proxying for expected subsidies, which is assumed to be orthogonal to the error term. Identification here is achieved through functional form assumptions. To make our approach manageable we aggregated the different kinds of state aids into a single binary variable: aid-no aid. Clearly, in doing so, we loose important details which are specific to our dataset. For this reason, in the next section we will not be able to provide additional information on the interplay of different instruments when applied to the same type of investment.

\subsection{Innovation Production Function}

We see the innovation process as a costly one, requiring investments both in R\&D and in fixed capital. While the first type of investment is obviously to be included in our specification, in our context we feel it is sensitive to include the second one as well. This captures the idea that new vintages of fixed capital are likely-even if 
not necessarily so-to incorporate relevant technological improvements which in turn may - or may not-allow for the development of product innovations. ${ }^{14}$ In addition, we also believe that it is reasonable to allow for complementarity/substitutability among the two types of investment. On the one hand, the process innovations could be in fact developed internally trough $\mathrm{R} \& \mathrm{D}$ activities or alternatively incorporated in new machinery acquired externally. On the other hand, the process of acquiring a new piece of machinery might require the hiring of an additional software developer with the purpose of making up/increasing the productivity of the new adopted technology.

We estimate binary response equations with logistic errors which are described by the following latent index models:

$$
\begin{aligned}
Y_{p i t}^{\star} & =\alpha_{1 f} I_{f i t}+\alpha_{1 r} I_{\text {rit }}+\alpha_{3 p}\left(I_{\text {fit }} * I_{\text {rit }}\right)+\mathbf{Z}_{i t}^{\prime} \beta_{p}+u_{\text {pit }} \\
Y_{\text {sit }}^{\star} & =\alpha_{2 f} I_{\text {fit }}+\alpha_{2 r} I_{\text {rit }}+\alpha_{3 s}\left(I_{\text {fit }} * I_{\text {rit }}\right)+\mathbf{Z}_{i t}^{\prime} \beta_{s}+u_{\text {sit }}
\end{aligned}
$$

where we denote by $Y_{\text {pit }}^{\star}$ and $Y_{\text {sit }}^{\star}$ the level of product/process innovation introduced at time $t$ by firm $i$. Those are latent variables: we only observe whether an innovation has been introduced or not, which is why we estimate binary outcome models. Let $I_{\text {fit }}$ and $I_{\text {rit }}$ denote the amount of investment in fixed and R\&D capital, while $\mathbf{Z}_{i t}$ is a set of explanatory variables for firm $i$ at time $t$ and $u_{k i t}$ is a shock to investment of type $k$ at time $t$ for firm $i$. The vector $\mathbf{Z}_{i t}$ includes firm size as measured by the log of sales in period $t$ as well as industry and area dummies. The error term is decomposed into two parts: $u_{k i t}=\omega_{i}+\varepsilon_{k i t}, k \in\{p, s\}$, where $\omega_{i}$ captures the firm's managerial ability while $\varepsilon_{k i t}$ represents a random i.i.d. shock which is assumed to be drawn after the investment decisions are made. Because of the discrete nature of the observed dependent variable it would be difficult to relax the assumption on the timing of the investment while also allowing for unobserved heterogeneity. In principle, however, it is possible that the amount of investment is related to a random opportunity which is incorporated in $\varepsilon_{k i t}$ and unobserved by the econometrician. ${ }^{15}$

The three columns of Table 19 show the result of logistic regressions for product innovation using the pooled data (first column), adopting a random effect approach (second column) and a "fixed" effect approach (third column). ${ }^{16}$ In running these regressions we included wave dummies and, where appropriate, industry and area dummies. The results of columns 1 and 2 are coherent with an optimistic view of the role of public subsidies: both investment in R\&D and in fixed capital have a positive

\footnotetext{
14 For example, the advent of an important technological improvement in computers like the microchip affects the production of cars only if assembly plants invest in new computers with microchips-as opposed to old computers with punched cards - and use them accordingly in the production of cars.

15 It would be reasonable to include in Eqs. (1) and (2) as regressors also the lagged investment variables to capture state dependency as typically done in the dynamic panel data literature. Under fairly general assumptions it would be possible to consistently estimate the parameter attached to this additional regressor without having to rely on a random effect approach. "Fixed" effect estimators such as the ones developed by Honoré and Kyriazidou (2000) and Bartolucci and Nigro (2010) would accomplish this task. However, the first estimator would need at least four data points while the second could in principle be implemented with three data points while having to deal with some interpretation issues. In absence of a fully specified economic model the interpretation of the estimates for our application would indeed be problematic.

16 Robust standard errors are in round brackets.
} 
Table 19 Probability of introducing a product innovation

\begin{tabular}{llll}
\hline $\begin{array}{l}\text { Dep var } \\
\text { Method }\end{array}$ & $\begin{array}{l}\text { Innoprod } \\
\text { Pooled logit }\end{array}$ & $\begin{array}{l}\text { Innoprod } \\
\text { RE logit }\end{array}$ & $\begin{array}{l}\text { Innoprod } \\
\text { Cond logit }\end{array}$ \\
\hline $\log$ (fixinv) & $0.297(0.089)$ & $0.321(0.102)$ & $0.606(0.413)$ \\
$\log$ (rdinv) & $0.459(0.100)$ & $0.492(0.120)$ & $0.753(0.420)$ \\
$\log$ (fixinv) $\log ($ rdinv) & $-0.029(0.014)$ & $-0.031(0.016)$ & $-0.072(0.060)$ \\
$\log$ (sales) & $-0.168(0.052)$ & $-0.180(0.059)$ & $0.112(0.514)$ \\
$\mathrm{N}$ & 2786 & 2786 & 203 \\
\hline
\end{tabular}

Robust standard errors in round brackets

Wave, industry and area dummies are omitted

$* p<0.10$

$* * p<0.05$

$* * * p<0.01$

impact on the probability of introducing an innovation. When computed at the mean, the marginal effect is equal to 0.051 for $\mathrm{R} \& \mathrm{D}$ and to 0.027 for fixed investment in column 1 . These two inputs also appear to be substitutes. ${ }^{17}$ Moreover firm size, whose proxy is the log of sales, has a negative impact. This might reflect inefficiencies which in bigger firms, everything else being the same, slow down the innovation process. When we adopt a "fixed" effect model, that investments of both types positively affect the probability of introducing a product innovation is less clear since the relevant coefficients are estimated less precisely. However the same qualitative message results from the third column. ${ }^{18}$

The results for an analogous exercise for process innovation are described in Table 20. Also in these regressions we included wave dummies and, whenever appropriate, industry dummies and area dummies. The qualitative results are similar to the ones for product innovation. As it can be seen from columns 1 and 2, both types of investment have a positive impact on the probability of introducing a process innovation. When computed at the mean, the marginal effect is equal to 0.035 for $R \& D$ and to 0.036 for fixed investment in column 1. Moreover there appears to be also in this case some degree of substitution between the two types of investment. ${ }^{19}$ As for product innovation, the results in the case of the "fixed" effect logit are less striking. As it can be seen from column 3 of Table 20 the parameters maintain their signs but are less precisely estimated.

Overall this set of results is coherent with our approach. Both fixed and R\&D investment are found to be important factors in explaining both process and product

\footnotetext{
17 As it is well known, in non-linear models the interaction coefficient $\alpha_{3 k}$ does not measure the crosspartial derivative of interest. This implies that the sign of $\alpha_{3 k}$ does not necessarily indicate the sign of the interaction effect (see Ai and Norton 2003). When computed correctly the full interaction term is negative and statistically significant for many observations. The average effect is equal to -0.007 and the corresponding average standard error is equal to 0.003 .

18 The lower precision of the estimates may be due to the fact that the sample size reduce from 2786 to 203 observations since only switchers contribute to the likelihood.

19 The average interaction effect is equal to -0.008 with an average standard error of 0.003 .
} 
Table 20 Probability of introducing a process innovation

\begin{tabular}{llll}
\hline $\begin{array}{l}\text { Dep var } \\
\text { Method }\end{array}$ & $\begin{array}{l}\text { Innoproc } \\
\text { Pooled logit }\end{array}$ & $\begin{array}{l}\text { Innoproc } \\
\text { RE logit }\end{array}$ & $\begin{array}{l}\text { Innoproc } \\
\text { Cond logit }\end{array}$ \\
\hline $\log$ (fixinv) & $0.389(0.092)$ & $0.406(0.104)$ & $0.559(0.410)$ \\
$\log$ (rdinv) & $0.419(0.102)$ & $0.436(0.116)$ & $0.691(0.453)$ \\
$\log$ (fixinv) $\log ($ rdinv) & $-0.033(0.014)$ & $-0.035(0.016)$ & $-0.077(0.066)$ \\
$\log$ (sales) & $-0.096(0.051)$ & $-0.100(0.054)$ & $0.986(0.843)$ \\
$\mathrm{N}$ & 2788 & 2788 & 210 \\
\hline
\end{tabular}

Robust standard errors in round brackets

Wave, industry and area dummies are omitted

$* p<0.10$

$* * p<0.05$

$* * * p<0.01$

innovation-albeit in different proportions. When assessing the effect of public subsidies on innovation output it is therefore crucial to analyze the effect of both fixed and R\&D investment subsidies, since they both might affect innovation output to the extent that they contribute to fostering their targeted innovation inputs.

\subsection{Expected Aids}

In order to deal with the endogenous nature of the public subsidies received by the firm we assume that the decisions to invest in R\&D and fixed capital are based on the expected fractions of the investment the firm believes will be financed by the government $(g)$. Specifically, in a model in which firms optimally make investments this is akin to assume that the amount of aids received by the firm is known only after the investments are decided. We regard this assumption on the timing of the events of the underlying model as an important identifying assumption.

Moreover, we also assume that such a state variable is related to observable firm characteristics through a known functional form. The definition of expected subsidies implies that $\mathbb{E}[g]=\operatorname{Pr}(g>0) \mathbb{E}[g \mid g>0]$. Therefore we need to model both the probability of receiving a public subsidy as well as its expected size. Moreover, in our case this needs to be done both for the investment in R\&D and for the investment in fixed capital.

In practice we relate these two objects to firm characteristics-assumed to be exogenous-which may enhance firm eligibility and/or willingness to apply. These include firm size (lsales) and age (age), dummies for legal status (legal), group (group) and consortium (consortium) membership and the quality of the workforce as measured by the share of workers with a high-school degree or more (education). Following González et al. (2005) we also include three additional variables with the purpose of capturing granting agency preferences: an export dummy (exporter) and two variables which proxy for the firm's geographical market (geomarket) and the average size of the competitors (compsize). In all the estimated equations we also include wave, area and industry dummies. 
Table 21 Probability of obtaining a subsidy-pooled logit estimation
Robust standard errors in round brackets

Wave, industry and area dummies are omitted

$* p<0.10$

** $p<0.05$

$* * * p<0.01$

\begin{tabular}{lll}
\hline & $(1)$ & $(2)$ \\
& dfixaid & drdaid \\
\hline lsales & $0.186 * * *(0.024)$ & $0.209 * * *(0.037)$ \\
age & $-0.000 *(0.000)$ & $0.003(0.002)$ \\
legal & $-0.277 * *(0.123)$ & $0.364(0.289)$ \\
group & $-0.221 * * *(0.066)$ & $-0.103(0.095)$ \\
consortium & $0.407 * * *(0.077)$ & $0.389 * * *(0.119)$ \\
education & $-0.141(0.099)$ & $0.232(0.159)$ \\
exporter & $-0.052(0.053)$ & $0.041(0.108)$ \\
geomarket & $0.193 * * *(0.056)$ & $0.295 * * *(0.083)$ \\
compsize & $-0.010(0.051)$ & $-0.103(0.081)$ \\
constant & $-2.418 * * *(0.493)$ & $-5.483 * * *(0.693)$ \\
$\mathrm{N}$ & 8132 & 4444 \\
\hline
\end{tabular}

As already mentioned in the previous section and in order to efficiently use our data and have enough observations to make the described approach feasible we aggregated the information on the type of state aid received by the firm. Thus we have a binary variable which takes the value of one if the firm received a grant and/or a soft loan and/or a tax credit and zero otherwise. In order to construct the expected subsidy variable we first model the probability of receiving an aid $(\operatorname{Pr}(g>0))$ in terms of a logit model. The first column in Table 21 shows the results for the probability of receiving an aid to fixed investment (dfixaid) while the second for the probability of receiving an aid to $R \& D$ investment (drdaid). The coefficients attached to wave dummies, industry dummies and area dummies are omitted. Except for the average competitor size variable, the education level and the export dummy, all other covariates are statistically significant in at least one of the two equations. Being large, belonging to a consortium and facing international competition are all factor which enhance the probability of obtaining a subsidy both to fixed and R\&D investment. Belonging to a group and having limited liability decrease instead the probability of obtaining an aid to fixed investment. We use these estimates to predict the probability that the firm will receive a subsidy of a given type and we denote the prediction as $\hat{p}$.

The second step requires to compute $\mathbb{E}[g]$ by regressing the (log of the) share of investment which is financed by some kind of aid on the same firm characteristics. Therefore, we model $\mathbb{E}[g \mid g>0]$ as a linear function of the same set of covariates: firm size and age, legal status, dummies for whether the firm belongs to a group or to a consortium, the education level of the employees, export status, geographical market size and the average competitor size. As usual wave, area and industry dummies are also included. The results are presented in Table 22 where we omit industry, time and area dummies to save on space. We can see that the share of investments financed by the government is negatively correlated to firm size: a $1 \%$ increase of sales implies a reduction of nearly $0.80 / 0.65 \%$ of the shares of fixed investments/investments in R\&D. Firm size is in fact the only significant regressor for the amount received for R\&D investment, in addition to some of the dummies we omitted from the table. On 
Table 22 Share of firm subsidies equations_-pooled OLS estimation

Robust standard errors in round brackets

Wave, industry and area dummies are omitted

$* p<0.10$

$* * p<0.05$

$* * * p<0.01$

\begin{tabular}{lll}
\hline & $(1)$ & $(2)$ \\
& lsfixaid & lsrdaid \\
\hline lsales & $-0.792 * * *(0.031)$ & $-0.658 * * *(0.056)$ \\
age & $-0.000^{* * *}(0.000)$ & $-0.001(0.003)$ \\
legal & $0.017(0.122)$ & $-0.092(0.381)$ \\
group & $-0.283^{* * *(0.073)}$ & $-0.151(0.132)$ \\
consortium & $0.008(0.081)$ & $-0.166(0.157)$ \\
education & $0.391 * * *(0.114)$ & $-0.284(0.224)$ \\
exporter & $-0.097(0.060)$ & $-0.018(0.160)$ \\
geomarket & $-0.204 * * *(0.063)$ & $-0.189(0.118)$ \\
compsize & $-0.018(0.059)$ & $-0.068(0.116)$ \\
constant & $5.593 * * *(0.475)$ & $4.633 * * *(0.738)$ \\
$\mathrm{N}$ & 2561 & 806 \\
\hline
\end{tabular}

the contrary belonging to a group and facing international competition has a negative impact (about $20 \%$ ) on the amount received for investments in fixed capital whereas the education level has a positive effect. Following González et al. (2005) we use the estimates in Table 22 to predict $\mathbb{E}[g \mid g>0]$. By exploiting log-normality, we then compute the expected subsidies as follows: $\hat{\rho}^{e}=\hat{p} \exp \left(\mathbf{Z}^{\prime} \hat{\lambda}+1 / 2 \hat{\sigma}^{2}\right)$, where $\mathbf{Z}^{\prime} \hat{\lambda}$ is the forecasted share of investment financed by the government.

\subsection{Investments Equations and R\&D Participation Decision}

We denote by $\hat{\rho}_{f}^{e}$ and $\hat{\rho}_{r}^{e}$ the predicted share of investment financed by public subsidies in fixed and $\mathrm{R} \& \mathrm{D}$ capital respectively. In order to assess if state aids have an impact on firm investment behavior we regress both whether or not to invest (extensive margin) and how much (intensive margin) on $\hat{\rho}_{f}^{e}$ and $\hat{\rho}_{r}^{e}$ as well as on the same set of covariates entering as explanatory variables in the equations commented upon in Sect. 4.4. Because most of the firms in our sample perform investment in fixed capital we only analyze the fixed investment effort decision. Table 23 reports the result of OLS regressions using the pooled data of the log of investments in R\&D and fixed capital on $\hat{\rho}_{f}^{e}$ and $\hat{\rho}_{r}^{e}$ (columns 1 and 3 ). We also replaced the expected subsidy variables with the corresponding predicted probabilities of receiving a subsidy $\left(\hat{p}_{f}\right.$ and $\left.\hat{p}_{r}\right)$, that is the first component in the expression for $\hat{\rho}_{f}^{e}$ and $\hat{\rho}_{r}^{e}$. This additional set of results is reported in columns 2 and 4 . We do so since we are not fully comfortable with our model ability to predict conditional expected subsidies out-of-sample, particularly for the R\&D investment case where the sample size is relatively small. Providing indirect evidence that the effects we might find are not sensitive to potential prediction fallacies is therefore an important addition to the credibility of our estimation strategy.

The main results can be summarized as follows. Firstly, an increase of $1 \%$ in the predicted probability of receiving a R\&D subsidy on R\&D investment generates an increase in R\&D investments of about $6.5 \%$ (column 2). Such an effect seems large: taken face value it implies that if each firm were to face a 10 per- 


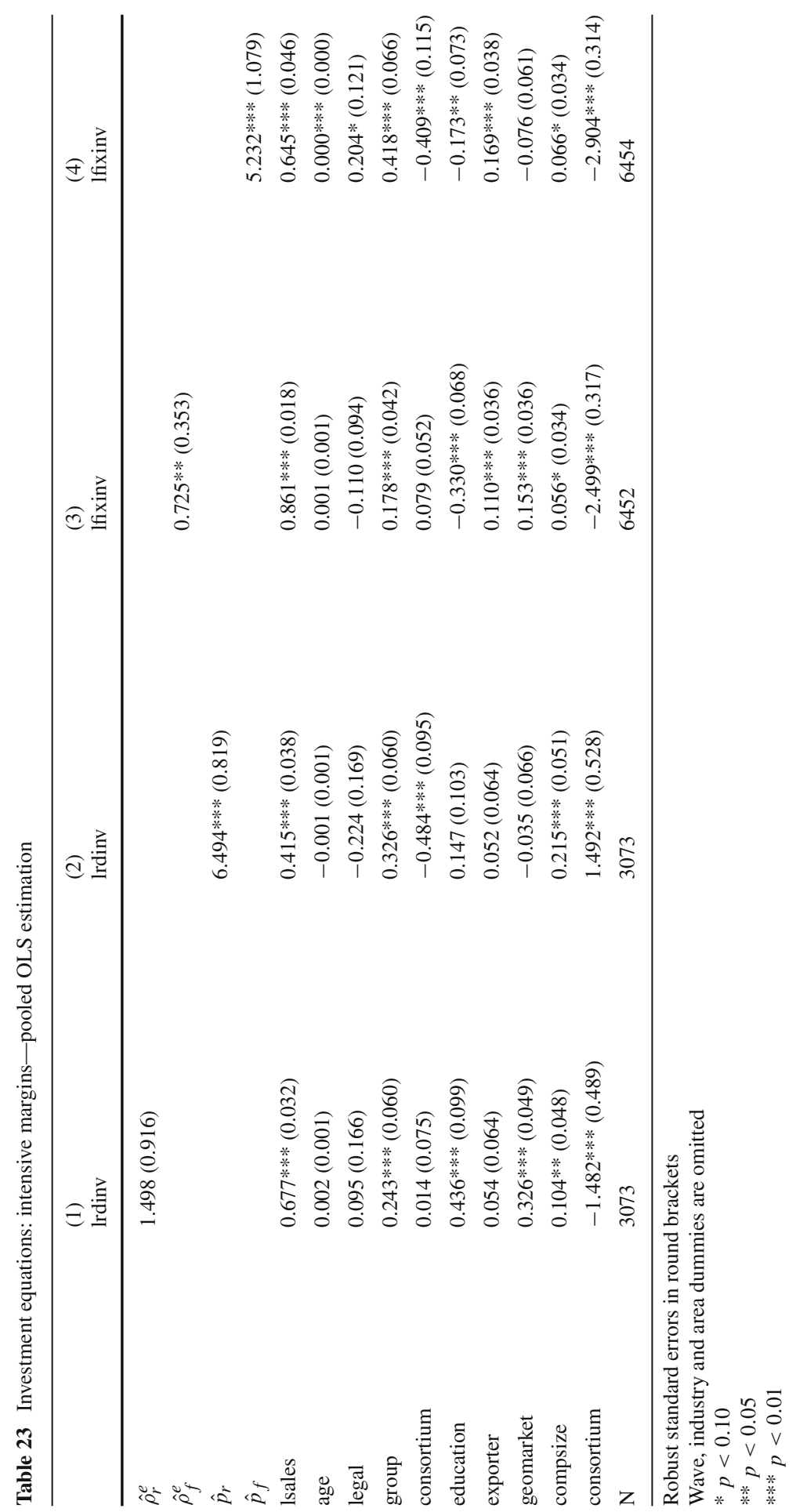


Table 24 Investment in R\&D: extensive margin—pooled logit estimation

Robust standard errors in round brackets

Wave, industry and area dummies are omitted

$* p<0.10$

$* * p<0.05$

$* * * p<0.01$

\begin{tabular}{lll}
\hline & $\begin{array}{l}(1) \\
\text { drdinv }\end{array}$ & $\begin{array}{l}(2) \\
\text { drdinv }\end{array}$ \\
\hline$\hat{\rho}_{r}^{e}$ & $-4.190(2.892)$ & \\
$\hat{p}_{r}$ & & $-2.872(4.654)$ \\
lsales & $0.203^{* * *}(0.067)$ & $0.310^{* * *}(0.073)$ \\
age & $0.005^{*}(0.003)$ & $0.005^{*}(0.003)$ \\
legal & $-0.634 *(0.343)$ & $-0.612^{*}(0.349)$ \\
group & $-0.034(0.155)$ & $-0.043(0.157)$ \\
consortium & $0.512(0.341)$ & $0.579 *(0.357)$ \\
education & $-0.064(0.219)$ & $-0.029(0.232)$ \\
exporter & $0.592^{* * *}(0.145)$ & $0.602 * * *(0.146)$ \\
geomarket & $0.363 * * *(0.137)$ & $0.411 * *(0.169)$ \\
compsize & $0.150(0.123)$ & $0.151(0.127)$ \\
constant & $2.492 *(1.310)$ & $1.874(1.387)$ \\
$\mathrm{N}$ & 2926 & 2926 \\
\hline
\end{tabular}

centage point increase in the probability of receiving a subsidy, the overall level of investments in R\&D would increase by more than $60 \%$. The partial elasticity of lfixinv with respect to the probability of receiving a fixed investment aid is smaller than the one we obtained for lrdinv: the coefficient drops to $5.2 \%$ (column 4). The effect of an increase in the size of expected R\&D on lrdinv, as shown in column 1 , is positive although it is not significantly different from zero at conventional statistical levels. Interestingly, as shown in column 3, the (partial) elasticity of lfixinv with respect to the expected subsidies turns out to be statistically significant (column 3): a $1 \%$ increase in the former generates a $0.7 \%$ increase of the latter.

Thirdly, larger firms invest more as one would probably expect: the (partial) elasticities are in the range of 0.4 to 0.8 depending on the specification adopted and on the type of investment. Also belonging to a group is a positive determinant of investments; here elasticities range from 0.1 to 0.4 . These estimates are consistent with the existence of financial constraints which are more likely to hit small firms and/or firms which cannot benefit from an internal capital market.

Finally, we also seek to explain the decision to engage into R\&D activities (extensive margin) by running an analogous set of regressions. The results of pooled logit estimates are presented in Table 24. The results indicate that both $\hat{\rho}_{R}^{e}$ and $\hat{p}_{R}$ do not increase the propensity to conduct $R \& D$ activity. ${ }^{20}$ It would then seem that government intervention does not have an impact on the extensive margin: firms would perform R\&D activity regardless of the expected amount of aids received and of the likelihood to receive such an aid.

\footnotetext{
20 Although the parameters are not significant at conventional statistical levels their negative signs are hard to interpret.
} 


\section{Conclusions}

In this paper we set ourselves the ambitious objective of building a sufficiently general empirical framework which allows the joint analysis of the effects of both R\&D and fixed investment subsidies on two different types of innovation outputs, namely product and process innovation. Our results suggest that firm subsidies affect innovation outputs through their role in enhancing innovation inputs. Our approach complements the existing literature which so far has focussed almost exclusively on the effect of R\&D subsidies on R\&D spending and, in a limited number of papers, on product innovation. In our view this is a major shortcoming since it is now commonly recognized that innovation comes in many different forms and that R\&D is only one-albeit obviously crucial-element of the innovation production function. Specifically, our work provides two pieces of evidence which are consistent with this view. Firstly, we provide robust descriptive evidence that show that different types of subsidies are positively correlated with fixed investment and R\&D spending even after allowing for individual effects and controlling for industry specific technology shocks. As long as unobserved heterogeneity at the firm level remains constant over time it is possible to give a causal interpretation to our estimates. Secondly, both R\&D and fixed investment are found to affect the probability of introducing product as well as process innovations. The first obvious implication of this finding is that there is something to be learnt in going over and beyond $R \& D$ subsidies when assessing the effect of firm subsidies on innovation outputs. The second, possibly less obvious, implication is that different types of innovation show different responses to different inputs. In this paper we indeed find that the marginal productivity of R\&D on product (process) innovation is higher (lower) than the marginal productivity of fixed investment. Therefore, not only we have to take into consideration different types of subsidies but also the fact that they may affect differently different types of innovation outputs. Assessing the efficiency of public policies towards firms remains an extremely challenging exercise for a variety of reasons, including the impossibility of running randomized experiments, the difficulties in measuring innovation and in collecting the relevant data over time in a consistent way. Still, by exploiting publicly available data we have been able to address some of the standard endogeneity concerns which plague this empirical literature.

Acknowledgments We thank participants at the two intermediate research seminars held at Irvapp for useful comments and suggestions. Special thanks to Erich Battistin, Michele Polo, Enrico Rettore and an anonymous referee for their insightful comments on previous drafts.

\section{References}

Aerts K, Schmidt T (2008) Two for the price of one? On additionality effects of R\&D subsidies: a comparison between Flanders and Germany. Res Policy 37(5):806-822

Ai CR, Norton EC (2003) Interaction terms in logit and probit models. Econ Lett 80(1):123-129

Almus M, Czarnitzki D (2003) The effects of public R\&D on firm's innovation activities: the case of Eastern Germany. J Bus Econ Stat 12(2):226-236

Bartolucci F, Nigro V (2010) A dynamic model for binary panel data with unobserved heterogeneity admitting a $\sqrt{n}$ consistent conditional estimator. Econometrica 78(2):719-733 
Benfratello L, Schiantarelli F, Sembenelli A (2008) Banks and innovation: microeconometric evidence on Italian firms. J Financ Econ 90:197-217

Bérubé C, Mohnen P (2009) Are firms that received R\&D subsidies more innovative? Can J Econ 42(1):206225

Busom I (2000) An empirical evaluation of the effects of R\&D subsidies. Econ Innov New Technol 9(2):111148

Czarnitzki D, Ebersberger B, Fier A (2007) The relationship between R\&D collaboration, subsidies and patenting activity: empirical evidence from Finland and Germany. J Appl Econ 22(7):1347-1366

Czarnitzki D, Licht G (2006) Additionality of public R\&D grants in a transition economy: the case of Eastern Germany. Econ Transit 14(1):101-131

David PA, Hall BH, Toole AA (2000) Is public R\&D a complement or substitute for private R\&D? A review of the econometric evidence. Res Policy 29(4-5):497-529

González X, Jaumandreu J, Pazó C (2005) Barriers to innovation and subsidy effectiveness. Rand J Econ 36(4):930-950

Honoré B, Kyriazidou E (2000) Panel data discrete choice models with lagged dependent variables. Econometrica 68(4):839-874

Hussinger K (2008) R\&D and subsidies at the firm level: an application of parametric and semiparametric two-step models. J Appl Econ 23(6):729-747

Ientile D, Mairesse J (2009) A policy to boost R\&D: does the R\&D tax credit work? In: EIB papers 14(1)

Lack S (2002) Do R\&D subsidies stimulate or displace private R\&D? Evidence from Israel. J Ind Econom L(4):369-389

Mairesse J, Mohenen P (2010) Using innovation surveys for econometric analysis. In: NBER working paper, no 15857

Organization for Economic Co-operation and Development (1992) The Oslo manual, 1st edn, Paris

Organization for Economic Co-operation and Development (1996) The Oslo manual, 2nd edn, Paris

Organization for Economic Co-operation and Development (2005) The Oslo manual, 3rd edn, Paris

Parisi ML, Schiantarelli F, Sembenelli A (2006) Productivity, innovation creation and absorption, and R\&D: micro evidence for Italy. Eur Econ Rev 50:2037-2061

Solow R (1959) Investment and technical progress. In: Arrow KJ, Karlin S, Suppes P (eds) Mathematical methods in the social sciences. Stanford University Press, Palo Alto

Wallsten SJ (2000) The effects of government-industry R\&D programs on private R\&D: the case of the small business innovation program. Rand J Econ 31(1):82-100 